\title{
Encontro com a Psicanálise: experiências de estágio em uma clínica-escola
}

\section{Encountering Psychoanalysis: internship experiences in a university clinic}

\section{Encuentro con el Psicoanálisis: la experiencia de prácticas en una clínica escuela}

\section{Cláudia Alquati Bisol*}

Universidade de Caxias do Sul, Caxias do Sul, Rio Grande do Sul, Brasil

\section{Raquel Alquatti**}

Universidade Federal do Rio Grande do Sul - UFRGS, Porto Alegre, Rio Grande do Sul, Brasil

\section{Thays Carvalho Gonem***}

Universidade de Caxias do Sul, Caxias do Sul, Rio Grande do Sul, Brasil

\begin{abstract}
RESUMO
A clínica-escola, enquanto espaço para realização de estágio em Psicologia Clínica, conjuga as dimensões da formação universitária e atendimento à comunidade. A Psicanálise é uma das modalidades clínicas e dispositivos teóricos que se apresentam aos estudantes como possibilidade para seu trabalho. Neste artigo, iniciamos problematizando as relações entre a Psicanálise e a Universidade, na tentativa de situar um lugar possível para a Psicanálise no contexto da formação em um curso de Psicologia. Em seguida, buscamos elementos para pensar a clínica nas recomendações de Freud aos jovens analistas. Por fim, articulamos estas questões à nossa experiência de estágio, realizado em uma clínica-escola de uma Universidade do sul do país. Consideramos que a desconstrução da lógica universitária em relação ao saber, a construção de uma escuta que não cede à linguagem e a atenção para o manejo das exigências institucionais são algumas das questões essenciais para um encontro possível dos estudantes com a Psicanálise.
\end{abstract}

Palavras-chave: clínica, psicanálise, estágio, psicologia.

\begin{abstract}
A university clinic, as a place for internship in clinical psychology, combines the dimensions of university education and service to the community. Psychoanalysis is one of the clinical modalities and theoretical perspectives presented to the students as a possibility for their work. In this article, we begin discussing the relations between psychoanalysis and the university, in an attempt to locate a possible place for psychoanalysis in the context of internship in a psychology course. Then, we seek elements to think the clinic
\end{abstract}


in Freud's recommendations to young analysts. Finally, we articulate these issues to our internship experience, held in a university clinic in the South of the country. We believe that the deconstruction of the university logic in relation to knowledge, the construction of a listening that does not yield to language and the attention to the management of institutional requirements are some of the essential issues for a possible encounter of students with psychoanalysis.

Keywords: clinic, psychoanalysis, internship, psychology.

\section{RESUMEN}

La clínica escuela, como un espacio para la realización de prácticas en psicología clínica, combina las dimensiones de la educación universitaria y el servicio a la comunidad. El psicoanálisis es una de las modalidades clínicas y dispositivos teóricos que se presentan a los estudiantes como una posibilidad para su trabajo. En este artículo, empezamos problematizando las relaciones entre el psicoanálisis y la universidad, en un intento de localizar un lugar posible para el psicoanálisis en el contexto de la formación en un curso de psicología. Luego, buscamos elementos para pensar la clínica en las recomendaciones de Freud a los jóvenes analistas. Por fin, articulamos estas cuestiones a nuestra experiencia de prácticas, que tuvo lugar en la clínica escuela de una universidad en el Sur del país. Consideramos que la deconstrucción de la lógica universitaria en relación al conocimiento, la construcción de una escucha que no cede en el lenguaje y la atención al manejo de las exigencias institucionales son algunas de las cuestiones esenciales para un encuentro posible de los estudiantes con el psicoanálisis.

Palabras clave: clínica, psicoanálisis, formación, psicología.

\section{I ntrodução}

Freud, no artigo Recomendações aos médicos que exercem a Psicanálise, de 1912, problematiza, de modo pontual e bastante didático, algumas das questões que se colocam para o médico que se inicia na prática da Psicanálise, destacando elementos da técnica e da ética que dizem respeito ao enquadre, à postura do analista e às intervenções. O texto de Freud, além de contribuir com questões relativas ao início da prática clínica, deixa um convite para pensar a adaptação do manejo clínico à instituição. O autor considera que em contextos institucionais algo poderia ser diferente do que ocorre na cena clínica tradicional. São essas provocações freudianas que fizeram com que nos voltássemos à clínica-escola como um espaço institucional de pesquisa, de reflexão e de escuta, onde pode se dar a iniciação e experimentação da prática clínica ao aluno de Psicologia a partir da Psicanálise, na Universidade.

É fato que os psicanalistas estão presentes nas Universidades e que a Psicanálise está inclusa nos currículos acadêmicos, sendo escolha de muitos alunos em fase de formação adentrar nessa seara. Neste campo tensionado entre a Universidade e a Psicanálise, temos a clínica-escola como possibilidade de entremeio: a Psicanálise ensinada em sala de aula permite ao aluno um contato com uma 
teoria. A clínica-escola, por sua vez, em sua função de local de estágio e de atendimento psicológico à população de baixa renda, propicia um encontro de outra ordem. Entre o contato e o encontro com a Psicanálise ao longo da formação universitária, principalmente ao término desta, no estágio em clínica, nos perguntamos: que clínica psicanalítica é possível em uma clínica-escola? Consideramos que esta pergunta é fundamental para o estudante de Psicologia em término de curso que se vê diante dos desafios de iniciar a sua clínica. Aqueles que escolhem fazer este caminho pela Psicanálise deparam-se com a necessidade de articular teorias complexas às demandas concretas trazidas por seus primeiros pacientes. Faz-se necessário lidar com os desafios de um novo lugar, que suscita questões da análise pessoal e da supervisão acadêmica.

Procuramos inicialmente problematizar as relações entre a Psicanálise e a Universidade, na tentativa de situar um lugar possível para a Psicanálise no contexto da formação em um Curso de Psicologia. Em seguida, buscamos elementos para pensar a clínica nas recomendações de Freud aos jovens analistas. Por fim, articulamos este trajeto a partir de nossa vivência de estágio realizado em uma clínica-escola de uma Universidade do sul do país.

Clínica-escola: contatos e encontros com a Psicanálise

Os estágios curriculares constituem-se no espaço para exercício da Psicologia no percurso da formação universitária. É ao longo dos estágios em Psicologia clínica que o estudante tem a oportunidade de se experimentar e construir o lugar de terapeuta.

De acordo com a Resolução $N^{\circ} 5$, de 15 de março de 2011, que institui as Diretrizes Curriculares Nacionais para os cursos de graduação em Psicologia, os estágios são configurados como "conjuntos de atividades de formação, programados e diretamente supervisionados por membros do corpo docente da instituição formadora" (Brasil, 2011, p.7), cujo objetivo é "assegurar o contato do formando com situações, contextos e instituições, permitindo que conhecimentos, habilidades e atitudes sejam concretizadas em ações profissionais" (Brasil, 2011, p.7). O Ministério da Educação recomenda:

O projeto de curso deve prever a instalação de um Serviço de Psicologia com as funções de responder às exigências para a formação do psicólogo, congruente com as competências que o curso objetiva desenvolver no aluno e as demandas de serviço psicológico da comunidade na qual está inserido (p. 8).

Neste contexto, os estágios clínicos dos cursos de graduação em Psicologia são, em sua maioria, exercidos em clínicas-escolas 
vinculados à Universidade. A clínica-escola pode ser descrita como o ponto de convergência entre os espaços acadêmico, clínico e institucional, um espaço ao mesmo tempo de formação universitária e de atendimento à comunidade (Marcos, 2011; J ordão, 2013). Tratase, portanto, de um espaço voltado à prática e à pesquisa na formação do estudante de Psicologia, ao mesmo tempo em que permite acesso ao atendimento psicoterápico a uma ampla parcela da população.

Por ser um serviço de saúde mental, a clínica escola apresenta características comuns a outras instituições de prestação de serviços, tais como uma clientela específica, diferentes modalidades de atendimento e um dado modo de funcionamento interno. Contudo, em que pese esteja inserida em um espaço universitário, diferenciase pelo propósito de reflexão e de pesquisa atrelado à prática (Marcos, 2011).

Neste contexto de construção de saberes, são várias as linhas teóricas que sustentam as práticas de estágio. O estagiário depara-se com a possibilidade de trabalhar com a diversidade de modalidades clínicas e de dispositivos teóricos, e, ainda, com sujeitos e com o sofrimento psíquico que trazem (Ribeiro, 2013). Desse modo, a clínica-escola está envolta em diferentes dispositivos de atuação clínica com diferentes relações de saber e de poder que tornam a clínica-escola um espaço de diferentes formas de trabalho, objetivos e olhares aos sujeitos.

Figueiredo (2008) faz uma retomada histórica do percurso de aproximação entre a Universidade, mais especificamente o campo da Psicologia, e a Psicanálise em contexto brasileiro. Segundo a autora, o primeiro serviço clínico disponibilizado para a população brasileira foi ofertado pela PUC-RJ, em meados dos anos 1960, e contava com a presença de estagiários. Psicanálise, Psicologia e Pedagogia encontravam-se atreladas ao serviço e os professores supervisores se vinculavam à Sociedade Brasileira de Psicanálise do Rio de Janeiro (SBPRJ). Sua relação com a Universidade não era muito clara, ora atuavam como professores e supervisores, ora como profissionais contratados. Já a seleção dos estagiários tinha como premissa a análise pessoal.

No Brasil, até os anos 80 , as sociedades vinculadas à IPA (International Psychoanalytical Association) vetavam aos psicólogos a formação em Psicanálise. Por intermédio da Universidade foi fundado em 1971 o Curso de Especialização em Psicologia Clínica na PUC-RJ, possibilitando aos psicólogos uma formação clínica psicanalítica sem, contudo, a concessão da titulação de psicanalista. Decorre o que a autora chama de uma Psicologia psicanalítica. Coloca-se, assim, a Universidade como um espaço possível de pensar a Psicanálise. Figueiredo (2008) ressalta que a partir dos anos 80 as instituições de formação em Psicanálise se abrem para a entrada de psicólogos, 
rejeitando o espaço da Universidade como um local de discussão e redefinição da Psicanálise. A autora aponta, ainda, que é nos anos 90 que emerge uma tensão envolvendo o espaço da Psicanálise nos cursos de Psicologia, já que é neste momento que os currículos são reestruturados de modo a dar conta das questões sociais e institucionais. "Dessa vez a Psicanálise corre o risco de perder sua especificidade, não mais para justificar a profissionalização dos psicólogos, mas para o atendimento à população de baixa renda que chega aos ambulatórios e aos serviços de saúde mental" (p. 240).

Nesta tensão que envolve a Psicanálise junto aos cursos de Psicologia, Kessler (2013) afirma que na atualidade da Universidade, a validade do saber psicanalítico é questionada em contraposição à gama de saberes que circundam o espaço psi, tais como "as indagações diagnósticas e a proposição do DSM-5; as proposições das teorias cognitivo-comportamentais ou os pós-estruturalistas deleuzianos, ambos tão díspares, mas tendo como consenso que a Psicanálise não teria mais tanta valia" (p. 39).

$\mathrm{Na}$ via dessas considerações, Rosa (2001) aborda o jogo de forças que se faz presente nos cursos de Psicologia no Brasil, e que reflete diretamente na construção dos currículos da formação em Psicologia. Este impasse se configura a partir de discussões de cunho teórico e político sobre como o sofrimento humano deve ser abordado. No campo da Psicologia, atualmente, há a busca de uma prática predominantemente voltada ao enfrentamento das questões sociais. A autora aponta que, no que toca à Psicanálise, a crítica que emerge muitas vezes diz respeito a uma compreensão errônea de sua clínica, como se o exercício desta modalidade de atuação negasse as mazelas sociais e fosse praticada de forma elitista, patologizante e individualizante. Fica posto, portanto, que há um embate entre duas lógicas de atuação. Enquanto há uma tendência de algumas correntes da Psicologia de partir do social para abarcar o sofrimento humano, a Psicanálise busca partir da escuta do sujeito para problematizar os processos do campo do político e do social.

As divergências entre a Psicanálise e a Psicologia são reiteradas na organização estabelecida pelos cursos de Psicologia, em que se subdividem o ensino teórico, em um primeiro momento, e o atendimento clínico e a supervisão, nos anos finais. Essa questão traz à cena a distância entre o ensino de uma teoria e a transmissão de um saber. Segundo Rosa (2001), a diferença se coloca no momento em que o debate teórico fornece a impressão de plenitude e de compreensão dos fenômenos, enquanto a transmissão opõe o saber e a verdade.

A questão da transmissão decorre da já mencionada tensão entre a Psicanálise e a Universidade. Freud, no texto Sobre o ensino da Psicanálise nas Universidades (Freud, 1919/1969), analisa as vantagens e desvantagens desta inserção. Embora reconheça a 
possibilidade de inclusão da Psicanálise nos currículos acadêmicos, Freud ressalta que esta independe das Universidades. Via de regra, o profissional interessado na área dependeria do amparo teórico da literatura, da análise pessoal e da supervisão. As sociedades psicanalíticas sustentam a formação de um analista. No que diz respeito à Universidade, Freud menciona as diferenças inerentes à estrutura da Psicologia acadêmica e a estrutura da Psicanálise.

A questão da transmissão da Psicanálise na Universidade, pois, suscita diferentes posicionamentos entre os autores. Marcos (2011) ampara-se no texto Cinco lições de Psicanálise, de Freud, no qual o autor afirma que é inviável a aprendizagem do método psicanalítico exclusivamente a partir da absorção dos fundamentos teóricos. Ou seja, a Psicanálise requer uma prática para que seja possível a sua transmissão. Figueiredo (2008), por sua vez, aponta que "a transmissão ultrapassa o ensino na medida em que se dá para além dele, na análise de cada um, na supervisão em que o analista dá provas de sua clínica, enfim, 'Psicanálise não se aprende só na escola', mas também nela" (p. 241).

A concepção lacaniana sobre os quatro discursos apresentados em $O$ avesso da Psicanálise - o discurso do mestre, da histérica, da Universidade e o analítico-, permite problematizar a questão da transmissão da Psicanálise na Universidade. Kessler e Ortmann (2012) anunciam a impossibilidade de a transmissão ocorrer pela posição característica do discurso universitário. Contudo, os autores se posicionam de modo a afirmar que algo da transmissão pode ocorrer na Universidade devido à possibilidade de o aluno se sentir capturado pela teoria e convidado a adentrar neste campo. Figueiredo (2008) se ancora no conceito de transferência, problematizando que a suposição de um saber está presente no jogo entre as posições dos discursos. No que tange à graduação, os psicanalistas que se encontram na posição do ensino podem, somente, oferecer um saber sobre a Psicanálise e, se possível, recolher os efeitos deste ensino sobre os alunos. Entretanto, a autora afirma que são as atividades de estágio na clínica que ofereceriam uma primeira chance de uma relação diferente com a Psicanálise no momento da graduação, "algo a partir do real que se apresenta na demanda feita ao aluno pelo paciente que busca o atendimento, e o coloca pela primeira vez em posição de dar algum destino a esta demanda que lhe é dirigida" (Figueiredo, 2008, p. 246).

O estágio clínico, no espaço propício da clínica-escola, é a via possível de algo da transmissão da Psicanálise na Universidade. Marcos (2011) afirma que:

A clínica abre um campo de pesquisa privilegiado na Universidade. Ela é o reconhecimento da necessidade de complementação do que se pode transmitir pela via do ensino 
formal e a afirmação e a apropriação pela própria Universidade de um espaço no qual a transmissão pode se dar de outro modo. Temos aí a dimensão da pesquisa e da produção de saber. A pesquisa estaria tanto do lado do aluno que conduz o atendimento quanto do supervisor que confirma ou não o que se ensina em sala de aula (p. 208).

Jordão (2013) discute a incompatibilidade das lógicas da ciência e da Psicanálise, apontando que o trabalho com a clínica psicanalítica na Universidade demanda a coexistência de um olhar à ciência e as questões da ética da Psicanálise. Faz-se necessária uma escolha entre uma ou outra posição. Surge então a discussão sobre a introdução dos preceitos éticos da Psicanálise no contexto da clínica-escola. Há uma concordância dos autores quanto o problema da análise pessoal dos alunos atuantes na clínica pelo viés da Psicanálise. Kessler e Ortmann (2012) e Rosa (2001) questionam a possibilidade de transmissão da Psicanálise a alunos que não passaram por um processo analítico: é possível a escuta do inconsciente do outro sem que tenha havido uma familiarização com a escuta do próprio inconsciente? Frente a tal pergunta, Marcos (2011) propõe uma alternativa:

Curiosamente, é no momento de iniciação a uma prática clínica que se coloca frequentemente para o aluno a questão da sua análise pessoal, apontando assim para além da Universidade. É na iniciação a este trabalho muito sutil de pescar a não-palavra que surge para o aluno a questão da sua própria análise. 0 encontro com a clínica na Universidade pode produzir, a partir desta relação particular com o saber que é requerida nesta experiência, um desejo de ir além (p. 218).

No encontro com a possibilidade de análise se faz possível o deslocamento do desejo de curar ao desejo que não se sustenta na certeza de um saber, mas sim em desejo do desejo do Outro, outra questão essencial na sustentação de uma ética psicanalítica (Ribeiro, 2013). A Psicanálise demanda um deslocamento em relação ao saber frente ao sujeito, pois "é recusando o desejo de ser mestre, de ser aquele que sabe a resposta que falta [...] que a análise pode ocorrer" (Marcos, 2011, p. 210). A construção do estágio a partir da Psicanálise, portanto, requer um deslocamento de posição frente ao saber constituído dentro da Universidade e abre espaço para um movimento do estudante, para que ele não mais esteja na posição de quem recebe um saber pronto e possa ocupar um lugar de construção de um saber a partir da demanda do outro.

É consenso entre os autores que o espaço de supervisão propicia subsídios para análise das questões que se fazem presentes nos 
atendimentos. Conforme Marcos (2011), a supervisão possibilita a implicação do aluno enquanto ator da construção do seu saber. Aluno e supervisor são então incitados à pesquisa. Neste processo, a autora coloca que:

Pode-se, a partir de um determinado aspecto da teoria, ordenar o que se escuta na clínica, escamoteando a singularidade que a experiência prática provoca. Ao contrário, a supervisão pode provocar uma produção de saber sobre o caso a partir daquele que recolhe o que é escutado na clínica, para a partir daí recorrer à teoria. A supervisão abriria espaço, então, para a possibilidade de uma prática que leve à produção de saber ( $p$. 208).

O espaço de supervisão é um meio de acolhimento do mal-estar que se coloca diante do deslocamento em relação ao saber (Jordão, 2013). Além disso, Rosa (2001) compreende que a supervisão pode auxiliar os estudantes na escuta dos casos, bem como no entendimento das diferentes subjetividades forjadas pelas demandas sociais.

As considerações aqui delineadas permitem que compreendamos que a clínica-escola é um lugar fundamental da relação entre Psicanálise e Universidade, pois possibilita que algo da transmissão possa ocorrer mediante a tomada de uma nova posição do estudante frente a sua relação com o saber. Nesta nova posição, nos permitimos a aprender algo a partir dos conselhos de Freud aos iniciantes no exercício da Psicanálise, para então significar nossa própria experiência enquanto estagiárias em uma clínica-escola de Psicologia.

As recomendações de Freud

No texto Recomendação aos médicos que exercem a Psicanálise, de 1912, Freud elenca nove aspectos norteadores para a prática psicanalítica e questões éticas referentes ao manejo do psicanalista iniciante em seu exercício. Estas questões são relevantes para o estagiário de Psicologia em atuação na clínica-escola.

Em um primeiro momento, Freud (1912/1969) faz uma explanação sobre 0 atendimento a mais do que um paciente, rejeitando 0 demasiado esforço por parte do psicanalista para lembrar-se de datas, nomes e relatos. Nesse sentido, recomenda a manutenção de uma atenção flutuante. $O$ autor considera não se tratar do trabalho de uma memória excepcionalmente boa, mas de que as informações em desordem trazidas pelos pacientes ao longo do processo de escuta devem ser postas em suspenso, podendo ser acessadas posteriormente, quando um novo elemento entrar para conectar os sentidos. Enfatiza, diante desta questão, que esquecimentos e 
equívocos raramente ocorrem, sendo que quando acontecem, podem derivar de perturbações de ordem pessoal do próprio analista.

A tomada de notas durante as sessões não é recomendada, uma vez que a atividade mental do analista fica presa em tal tarefa e produz uma seleção do material a ser registrado. Freud comenta a tomada de notas como meio de elaboração de estudos científicos, argumentando, porém, que relatórios exatos de histórias clínicas não conseguem traduzir a análise. Para o autor, mesmo que a técnica psicanalítica requeira o exercício de pesquisa, não é aconselhado o trabalho científico sobre um caso não finalizado, uma vez que pode demandar expectativas desnecessárias que podem levar à sua condução equivocada.

Freud adentra a questão do desejo do analista, pontuando que "o sentimento mais perigoso para um psicanalista é a ambição terapêutica de alcançar, diante este método novo e muito discutido, algo que produza efeito convincente sobre outras pessoas" (Freud, 1912/1969, p. 128). Esta ambição produziria o efeito de impotência frente às resistências do paciente. $\mathrm{O}$ que poderia ser entendido como "frieza emocional" traz vantagem para o sujeito que realiza o atendimento, uma vez que é uma proteção para sua própria vida emocional e para o paciente, sendo, segundo Freud "o maior auxílio que Ihe podemos hoje dar" (1912/1969, p. 129).

O texto discute também o papel do inconsciente do psicanalista como um órgão receptor que deve ser capaz de reconstituir os fragmentos de inconsciente fornecidos pelo sujeito e devolvê-los a ele. Neste ponto, Freud enfatiza a questão da análise pessoal, uma vez que "toda repressão não solucionada nele (o analista) constitui [...] um ponto cego em sua percepção analítica" (1912/1969, p. 130).

A exposição da individualidade do analista na cena clínica é reprovada por Freud, uma vez que dificulta a transferência, objeto primordial da análise. "O médico deve ser opaco aos seus pacientes e, como um espelho, não mostrar-lhes nada, exceto o que lhe é mostrado" (Freud, 1912/1969, p. 131). Neste tópico Freud problematiza a clínica em contexto institucional, apontando que nas instituições pode ser necessária a combinação da análise com certa influência sugestiva a fim de chegar a algum resultado num período mais curto de tempo. “Mas é lícito insistir em que ele próprio não se ache em dúvida quanto ao que está fazendo e saiba que o seu método não é o da verdadeira Psicanálise" (Freud, 1912/1969, p. 131).

Assim como as experiências pessoais do analista, as atividades educativas são desaconselhadas por Freud (1912/1969), pois a indicação de novos objetivos para os analisantes desloca a ênfase para o desejo do analista ao invés do desejo dos pacientes. O autor recomenda aos analistas que se contentem com aquilo que o paciente julga como bom para si, pois "a ambição educativa é de tão pouca utilidade quanto a ambição terapêutica" ( $p$. 132). Também a 
atribuição de tarefas ou indicações de reflexão sobre determinado momento de vida do paciente são contraindicadas, visto que não contribuem para a resolução de seus enigmas. Ao contrário, a resolução de um enigma do paciente só é possível quando a regra fundamental da Psicanálise for respeitada.

Freud alerta sobre o desvio para a atividade intelectual de alguns pacientes que, ao teorizarem muito bem sobre si, evitam fazer algo para superar suas dificuldades. Em razão disso, fica explícito o motivo pelo qual o autor se furta da indicação de material teórico que explique a Psicanálise aos pacientes e familiares, pois a experiência do autoconhecimento advinda do processo de análise é certamente mais rica do que o ato de se debruçar sobre a teoria.

Experiências de estágio: uma clínica psicanalítica possível

Se, como dito anteriormente, a Psicanálise demanda um deslocamento, não centraremos de imediato a discussão das questões propostas a partir do referencial anteriormente abordado. Traremos antes nossa vivência e, a partir dela, procuraremos esboçar algo acerca do encontro com a Psicanálise no estágio de Psicologia clínica em uma clínica-escola.

A clínica-escola em questão situa-se em uma Universidade Comunitária que tem compromisso de ofertar serviços à comunidade local. Esta clínica atua há trinta e dois anos prestando atendimento psicoterápico à população local. No ano de 2011, o serviço passou a ter convênio com o sistema de saúde municipal, passando a atender a demanda proveniente da rede de saúde pública da cidade. A demanda que chega ao serviço nem sempre é espontânea, uma vez que grande parte dos usuários é encaminhada por profissionais ou instituições do município que os endereçam ao serviço, com o objetivo de requerer pareceres ou avaliações que respondam algo sobre seus sintomas.

Iremos atentar à lógica da relação ensino-aprendizagem que permeia, antes de tudo, o espaço da clínica-escola. O percurso universitário é marcado por uma relação hierárquica na qual um mestre transmite algo que deve ser apreendido pelo aluno e comprovado por meio de instrumentos avaliativos. As evidências deste funcionamento apontam para uma relação de causalidade, em que quanto mais o aluno se empenha em aprender algo sobre as teorias, por meio de frequência às aulas, participações, leituras e pesquisas, mais ele estará apto a avançar em sua formação.

Compreendemos que a aprendizagem nestes moldes não é exclusividade do ensino universitário, tampouco consideramos este modelo improdutivo. Ao contrário, a partir desta lógica entendemos que é possível transitar pelo conhecimento. A entrada em estágio, 
contudo, desacomoda esta relação tão bem estabilizada ao longo de todo um percurso acadêmico.

$\mathrm{Na}$ atuação em estágio, a responsabilidade extrapola as tarefas comumente atribuídas a um estudante e passa a envolver a complexidade de uma ética pelo exercício profissional e, principalmente, pelo outro. É um protagonismo que se faz necessário na contramão do invólucro da sala de aula. Neste lugar não há um professor prescritor da tarefa, mas um supervisor. Na supervisão o material provém da ação do estagiário e, sem este, a tarefa do supervisor é vazia, nada da construção é possível.

Em que pese exista esta inversão, a avaliação deste processo se estabelece na dependência de uma comprovação de resultado ilustrado a partir de exigências formais, que incluem relatórios e estudos de caso cujo formato varia de acordo com as exigências do supervisor. Além disso, há um protocolo no que diz respeito à clínicaescola enquanto instituição, que envolve prestação de contas. No caso de nossa experiência, ressaltamos alguns procedimentos que abarcam o cumprimento de uma carga horária específica, a disponibilização de horários determinados para atendimento, duração e quantidade de sessões concedidas - nos moldes de uma terapia de cunho breve -, orientações ao paciente sobre o funcionamento da instituição, o estabelecimento de limites de faltas, bem como preenchimento de documentação, fixação de um contrato formal e registros de prontuário.

Neste jogo, instaura-se um espaço de experiência que oscila em um duplo lugar em que não estamos na sala de aula tampouco distante dela. Não respondemos como profissionais, mas também não estamos isentos da responsabilidade de agirmos como tal. Pensamos neste espaço como uma encruzilhada, onde de um lado apresenta-se a via do sujeito e seu sofrimento e, de outro, a instituição e suas normas.

Esta situação gera no estagiário um conjunto de sentimentos intensificados nos primeiros contatos com a experiência clínica. Neste momento, o estudante ainda se encontra imerso na lógica da estabilidade, da ilusão de deter um saber a partir do qual forneceria respostas. Todavia, a prática clínica institui um outro sentido em que impera o vazio, o enigma e o não saber. $O$ paciente vem com uma queixa endereçada ao estagiário e, em contrapartida, não há respostas a esta demanda.

Ao retomar a experiência de nossa passagem por este momento, destacamos a vivência de sentimentos que marcaram o exercício inicial de escutar o outro. Recordamos a ansiedade e a expectativa de poder estar nessa nova posição que fora tão bem delineada em sala de aula nos anos anteriores. Mas a familiaridade teórica também gerava insegurança de transitar nesse novo campo e temor de não corresponder àquilo que parecia tão sólido. 
O encontro com a clínica pautado na tentativa de respeitar um manejo embasado na Psicanálise trazia inquietações sobre o não saber diante dos conteúdos aparentemente desconexos trazidos pelo paciente. Neste momento, ainda era automática a seguinte associação: se não sabes o que fazer, és teoricamente insuficiente. Esta é uma evidência das incompatibilidades existentes entre a Psicanálise e a Universidade, anteriormente descritas. Neste sentido, saber algo sobre a Psicanálise não é suficiente, há que construir a partir dela. Dito de outro modo: ter tido contato com a Psicanálise não é suficiente. Faz-se necessário ir ao seu encontro.

Neste intervalo, a supervisão constitui uma possibilidade do aluno situar-se diante dos espaços que Ihe soam tão desconexos. É o momento de supervisão que abre a possibilidade do desligamento de uma precisão acadêmica e de suportar o não saber, já que no próprio supervisor há um vazio de respostas aos enigmas do paciente. Outra questão remete ao lugar deste professor que agora, enquanto supervisor, irá propor uma relação diferente daquela de sala de aula. Não mais o lugar de mestre, mas de quem se propõe a escutar o fazer da clínica e, a partir disso, trabalhar a escuta possível do estagiário a seu paciente.

Essas considerações condizem com o que os autores anteriormente referidos afirmam sobre o momento de supervisão como um espaço propício para a produção de um saber/fazer, e não mais de reprodução do conhecimento. Identificamos, contudo, um aspecto que não foi contemplado pelos autores antes mencionados: a sutileza dessa posição que, ao mesmo tempo em que convoca o aluno a lidar com o esvaziamento de respostas, exige dele uma forma de comprovação de seu fazer. Cabe ao supervisor exigir comprovações a partir da clínica e convertê-las em uma nota, respondendo aos ditames acadêmicos, ao mesmo tempo em que sustenta o espaço para o não saber propício para o enigma que a clínica convoca.

Acreditamos que é a partir de uma autorização em supervisão que o aluno pode realizar uma torção, permitindo o desapego da restrição à teoria que pode vir a enclausurar o pensamento, para que assim possa haver uma abertura para escutar o outro, e a outra cena que aparece em seu discurso. Esta torção consiste em um movimento de escuta que se desprende do conteúdo e que busca não ceder nas palavras, assim como Freud nos ensina em A intepretação dos sonhos (1900-1901/2006). A fala do analisante deve ser tomada como um texto cifrado a ser lido e interpretado, como um hieróglifo requer uma leitura específica para ser desvendado.

No início dos atendimentos, é comum que a preocupação do estagiário esteja voltada aos fatos trazidos pelo paciente. Gradativamente, o estagiário começa a dar lugar àquilo que está além da conversa, no momento em que começa a atentar para as diferentes cenas enunciativas que aparecem no discurso do paciente, 
para as rupturas, recuos, equívocos de linguagem e interrupções na fala.

A tomada de uma nova posição do aluno também ocorre no momento em que ele tem condições de resguardar a cena clínica das exigências acadêmicas e institucionais da clínica-escola, não permitindo que este espaço seja inundado por preocupações de ordem avaliativa acerca do seu papel enquanto estagiário ou pelas regras de funcionamento da instituição. Quando este cuidado é possível, algo da Psicanálise pode ser esboçado.

Entendemos que neste caminho é possível refletir acerca das recomendações descritas por Freud, que desaconselha a tomada de notas integrais durante a sessão, a preocupação com a absorção total das informações pela memória e a realização de estudos de caso durante o processo. Todavia, tais recomendações foram destinadas a jovens analistas, e o momento de estágio, de experimentação, consiste em uma etapa anterior onde ainda não se sustenta a autonomia desta posição. O estagiário ainda se vê diante da entrega de relatórios, apresentação de sessões dialogadas e de estudos de caso em andamento.

Freud propõe o manejo centrado na escuta do paciente, indicando a não necessidade de uma comprovação de efeitos precoces da análise. Em um contexto de estágio onde a comprovação da prática circunda o fazer, a ambição terapêutica descrita por Freud se coloca frente ao estudante. Este se vê diante da necessidade de suspender esta ambição e, ao mesmo tempo, ilustrar a efetividade de seu percurso acadêmico no espaço da prática. Na medida em que se colocam todas estas dúvidas, o estudante não passa ileso.

Isto também remete a questão da análise pessoal, o que interpretamos como uma das recomendações centrais no texto de Freud. Compreendemos que o início da atividade clínica traz a necessidade de análise do próprio estagiário como uma convocação. O espaço de análise constitui uma possibilidade de o estagiário entrar em contato com suas próprias questões. Contudo, este é um ponto bastante delicado, visto que a graduação em Psicologia não tem requisito de tal ordem. Acreditamos que a importância da análise pessoal do estagiário é consonante à própria torção necessária do pensar a partir de um referencial psicanalítico, além de tocar um dos pilares de sustentação da teoria. Ademais, a passagem pelo processo de análise permite uma aproximação daquilo que Freud descreve como frieza emocional, que compreendemos como a habilidade de tirar de cena a individualidade daquele que assume o papel de analista.

A reflexão do fazer é uma constante, uma vez que o terreno da prática nunca está assentado e o questionamento é inerente ao processo como forma de consolidação de um lugar. O trajeto, contudo, não é linear e a construção desta posição não se dá de 
modo cumulativo. Quanto mais se percorre este caminho, mais questões se colocam. Isso nos leva a considerar este percurso como um processo contínuo e não como uma etapa a ser atingida. O tempo de estágio clínico - em nosso caso três semestres -, possibilita o início da construção de uma posição e não a conquista de um patamar. $O$ estágio diz muito mais de uma abertura do que de um fechamento.

$\mathrm{O}$ que Freud nos mostra ao desaconselhar a utilização de recursos e técnicas pré-estabelecidas é que somente a partir da fala emergente do paciente que é possível o encontro com o inconsciente. $\mathrm{Na}$ construção que fazemos até então sobre as possibilidades de inserção da Psicanálise em um contexto institucional, a discussão acerca das tensões e das regras que se sobrepõem ao tratamento não se faz suficiente. Neste entorno, para além das questões que permeiam o fazer do estagiário, há um sujeito que vem complementar a cena de uma clínica possível. Um sujeito que foi encaminhado, mas que acolhe o espaço da clínica-escola como um lugar possível de produção sobre si.

Freud comenta brevemente em seu texto a possibilidade de uma flexibilização do manejo do psicanalista no contexto das instituições em vista de um limitado período de tempo. O que ele nos indica é a afirmação da possibilidade de existência da Psicanálise fora do setting tradicional. Havendo na clínica-escola a lógica predominante da demanda por encaminhamento e, além disso, regras que estabelecem um limite de tempo e de faltas, cabe perguntar: como os sujeitos se vinculam?

Figueiredo (1997), ao abordar a clínica psicanalítica no contexto dos ambulatórios de saúde pública, compreende que os atravessamentos institucionais não são necessariamente impeditivos ao processo. Nas instituições de saúde pública, em que a questão do pagamento da análise é ausente, as regras de duração e das faltas, por vezes, se prestam à função do estabelecimento de um comprometimento do paciente com o processo. A problemática do tempo que se faz presente na realidade institucional é, de toda forma, uma questão para a Psicanálise. Para a autora, há que se considerar uma realidade psíquica que se sobrepõe à realidade institucional.

Há na clínica-escola um espaço propício para que um atendimento psicológico possa acontecer, se considerarmos que alguns elementos mais básicos ali existem, tais como uma sala e um horário reservado ao paciente e a garantia de um estagiário disponível para acolhê-lo. Em suma, sobretudo, este espaço institucional é um convite para que o paciente possa endereçar seu sofrimento a um outro que se propõe a escutar. O que se produz a partir daí, verte no caminho da transferência que pode se dar neste encontro e produzir, então, aquilo que é da ordem da outra cena. É justamente a partir do estabelecimento de um laço que enreda o sujeito, seu sofrimento e o 
endereçamento de sua questão a um outro atento a sua fala, que algo da Psicanálise pode ocorrer.

\section{Considerações finais}

A discussão esboçada ao longo deste trabalho deriva da nossa experiência em período de estágio e das inquietações emergentes em momentos de supervisão, que culminaram em uma reflexão sobre o espaço intervalar entre o ingresso no exercício da Psicanálise e a possibilidade de prática ofertada pela clínica escola.

Constatamos que a totalidade dos materiais pesquisados se constituem da observação de pesquisadores cujo percurso em Psicanálise está consolidado. Do lugar de estagiário, lugar este de início de um percurso, partem uma série de questionamentos e inquietações que não são abarcadas por estes autores. Acreditamos, pois, na relevância de tratar da questão da Psicanálise na clínicaescola a partir de nossa vivência.

$\mathrm{Na}$ tentativa de esboçar as relações que se estabelecem entre a Psicanálise e a clínica-escola, nos deparamos com questões que reclamam presença neste debate, em especial o atravessamento do saber acadêmico e da ética da Psicanálise. Entretanto, consideramos que a abertura desses questionamentos suscita diversas outras discussões que extrapolam os objetivos deste trabalho.

Frente à questão que propomos abordar neste estudo, acreditamos que uma construção possível sobre que clínica psicanalítica é possível na clínica-escola passa por um movimento de construir uma prática que se permite descolar da lógica universitária como forma de criar uma abertura para que o sujeito possa se filiar à cena clínica, trazendo sua questão.

\section{Referências}

Brasil, Ministério da Educação. (2011). Resolução № 5, de 15 de março de 2011. Brasília, DF. Recuperado de http://portal.mec.gov.br/index.php?option=com_docman\&view =download\&alias=7692-rces005-11-pdf\&category_slug=marco2011-pdf\&I temid $=30192$

Figueiredo, A. C. (1997). Vastas confusões e atendimentos imperfeitos: a clínica psicanalítica no ambulatório público. Rio de Janeiro, RJ: Relume-Dumará.

Figueiredo, A. C. (2008). Psicanálise e Universidade: reflexões sobre uma conjunção ainda possível. Fractal Revista de Psicologia, 20(1), 237-252. 
Freud, S. (1900/2006). A Interpretação de Sonhos. (J. Salomão \& J. O. A. Abreu Trad.). In J. Salomão (Ed.). Edição Standard brasileira de obras completas de Sigmund Freud. Rio de Janeiro, RJ : I mago.

Freud, S. (1912/1969). Recomendações aos médicos que exercem a Psicanálise. In J. Salomão (Ed.), Edição Standard brasileira de obras completas de Sigmund Freud. (Vol. 12, pp. 147-159). Rio de Janeiro, RJ : I mago.

Freud, S. (1919/1969). Sobre o ensino da Psicanálise nas Universidades. In J. Salomão (Ed.), Edição Standard brasileira de obras completas de Sigmund Freud. (Vol.17, 217-219). Rio de Janeiro, RJ : I mago.

Jordão, A., B. (2013). A clínica no contexto da Universidade: limites e possibilidades. Correio APPOA, 224, 29-35. Recuperado de http://www. appoa.com. br/uploads/arquivos/correio/224.pdf.

Kessler, C., H. (2013). Linhas de contexto das clínicas de Universidades, Correio APPOA, 224, 29-35. Recuperado de http://www.appoa.com. br/uploads/arquivos/correio/224.pdf.

Kessler, C. H., \& Ortmann, E. S. (2012). Psicanálise e Universidade: considerações a partir de uma experiência de prática em clínica na Universidade. Cadernos de Psicanálise (Rio de Janeiro), 34(27), 141-151.

Marcos, C. M. (2011). Reflexões sobre a clínica-escola, a Psicanálise e sua transmissão. Psicologia Clínica, 23(2), 205-220. Recuperado

de http://www.scielo.br/scielo. php?script=sci_arttext\&pid=S010356652011000200013\&Ing=en\&tIng=pt.10.1590/S010356652011000200013.

Ribeiro, M. S. M. (2013). Limites e possibilidades da clínica na Universidade. Correio APPOA, 224, 15-23. Recuperado de http: // www. appoa.com. br/uploads/arquivos/correio/224. pdf.

Rosa, M., D. (2001). Psicanálise na Universidade: considerações sobre o ensino de Psicanálise nos cursos de Psicologia. Psicologia USP, 12(2), 189-199. Recuperado de http://www.scielo.br/scielo.php?script=sci_arttext\&pid=S0103$65642001000200016 \&$ Ing $=$ en\&tIng $=$ pt.10.1590/S010365642001000200016 . 


\section{Endereço para correspondência}

\section{Cláudia Alquati Bisol}

Universidade de Caxias do Sul

Rua Francisco Getúlio Vargas, 1130, CEP 95070-560, Caxias do Sul - RS, Brasil

Endereço eletrônico: cabisol@ucs.br

\section{Raquel Alquatti}

Universidade Federal do Rio Grande do Sul

Av. Bento Gonçalves, 9500, CEP 91540-000, Porto Alegre - RS, Brasil

Endereço eletrônico: r.alquatti@gmail.com

\section{Thays Carvalho Gonem}

Universidade de Caxias do Sul

Rua Francisco Getúlio Vargas, 1130, CEP 95070-560, Caxias do Sul - RS, Brasil

Endereço eletrônico: thaysgonem@gmail.com

Recebido em: 05/06/2016

Aceito em: 13/04/2017

\section{Notas}

* Psicóloga pela Universidade de Caxias do Sul. Mestre e Doutora em Psicologia pela Universidade Federal do Rio Grande do Sul. Docente do Curso de Psicologia e do Pós-Graduação em Educação da Universidade de Caxias do Sul. Membro da Escola de Estudos Psicanalíticos.

** Psicóloga graduada pela Universidade de Caxias do Sul. Mestranda no Programa de Pós-graduação em Letras da Universidade Federal do Rio Grande do Sul.

*** Psicóloga graduada pela Universidade de Caxias do Sul. Mestranda no Programa de Pós-graduação em Educação da Universidade de Caxias do Sul.

Este artigo de revista Estudos e Pesquisas em Psicologia é licenciado sob uma Licença Creative Commons Atribuição-Não Comercial 3.0 Não Adaptada. 